\title{
Changes in Surface Charge Density of Blood Cells in Fatal Accidental Hypothermia
}

\author{
Michał Szeremeta ${ }^{1}$ - Aneta Dorota Petelska ${ }^{2}$ Joanna Kotyńska ${ }^{2} \cdot$ Witold Pepiński $^{1}$. \\ Monika Naumowicz $^{2} \cdot$ Zbigniew Artur Figaszewski $^{2,3} \cdot$ Anna Niemcunowicz-Janica ${ }^{1}$
}

Received: 26 March 2015/ Accepted: 4 September 2015/Published online: 12 September 2015

(C) The Author(s) 2015. This article is published with open access at Springerlink.com

\begin{abstract}
The objective of this research was to evaluate postmortem changes concerning electric charge of human erythrocytes and thrombocytes in fatal accidental hypothermia. The surface charge density values were determined on the basis of the electrophoretic mobility measurements of the cells conducted at various $\mathrm{pH}$ values of electrolyte solution. The surface charge of erythrocyte membranes after fatal accidental hypothermia increased compared to the control group within whole range of experimental $\mathrm{pH}$ values. Moreover, a slight shift of the isoelectric point of erythrocyte membranes towards high $\mathrm{pH}$ values was observed. The surface charge of thrombocyte membranes in fatal accidental hypothermia decreased at low $\mathrm{pH}$ compared to the control group. However, at $\mathrm{pH}$ range 4-9, the values increased compared to the control group. The isoelectric point of thrombocyte membranes after fatal accidental hypothermia was slightly shifted towards low $\mathrm{pH}$ values compared to the control group. The observed changes are probably connected with the partial destruction and functional changes of the blood cell structure.
\end{abstract}

Keywords Fatal accidental hypothermia $\cdot$ Surface charge density $\cdot \mathrm{pH}$ measurement . Erythrocyte . Thrombocyte

Michał Szeremeta

michalszeremeta@gmail.com

1 Department of Forensic Medicine, Medical University of Bialystok, Waszyngtona St. 13, 15-230 Bialystok, Poland

2 Institute of Chemistry, University of Bialystok, K. Ciolkowskiego St. 1K, 15-245 Bialystok, Poland

3 Laboratory of Electrochemical Power Sources, Faculty of Chemistry, University of Warsaw, Pasteur St. 1, 02-093 Warsaw, Poland

\section{Introduction}

Hypothermia occurs when the core body temperature is $35^{\circ} \mathrm{C}$, and in such a situation, it is classified as mild. Within the range of $32-28{ }^{\circ} \mathrm{C}$, hypothermia is defined as moderate and as severe at $<28{ }^{\circ} \mathrm{C}$ (Mallet 2002). There are different ways of classifying hypothermia; the simplest one is to divide fatalities into those occurring in dry environment-on land and those occurring in water-that is in wet environment or immersion hypothermia (Palmiere et al. 2014a, b). Until the 50s of the twentieth century, there was a popular misconception that the death due to hypothermia concerns individuals living outdoors, in an environmental with temperature below $0{ }^{\circ} \mathrm{C}$. However, according to the current state of knowledge, death caused by hypothermia may occur when the ambient temperature is between $0{ }^{\circ} \mathrm{C}$ and $+10^{\circ} \mathrm{C}$. The degree of susceptibility to hypothermia is an individual matter.

Due to non-specific findings, the postmortem diagnosis of hypothermia is problematic. During the autopsy, macroscopic features of hypothermia usually include pink discoloration of the skin, especially around the elbows and knees (the so-called frost erythema), red lividity, red blood, hemorrhagic spots of the gastric mucosa (Wiszniewski's spots), pancreatitis hemorrhages, synovial membrane hemorrhages, and hemorrhages into the large muscles of the body, especially into iliopsoas muscle (Tsokos et al. 2006; Bright et al. 2013).

On the other hand, pathophysiological changes associated with fatal accidental hypothermia are well described as effects in cardiovascular system, hematology, neuromuscular, and respiratory systems (Mallet 2002; Zhu et al. 2002, 2006a, b, 2007a, b, c). One can indicate gastrointestinal effects and renal and metabolic irregulations as well (Zhu et al. 2002, 2005; Quan et al. 2010). It is also 
possible to characterize the chemical and biochemical features of being exposed to cold. Postmortem biochemical examination revealed few issues connected to acid-base, electrolyte, fluid balance, catecholamines, and keton bodies in cases of fatal accidental hypothermia (Mant 1964, 1969, Hirvonen 1976; Hirvonen and Huttunen 1982; Zhu et al. 2007a, b; Li et al. 2009; Jakubeniene et al. 2009a, b; Ishikawa et al. 2010).

When it comes to coagulation system, it is a balanced combination of prothrombotic, anticoagulant, and fibrinolytic processes which is complex yet delicate. According to popular conception, hypothermia reduces coagulation and platelet function and impairs primary and secondary hemostasis. The hematological changes connected to hypothermia result from the increase in blood viscosity, fibrinogen, and hematocrit. These alternations can cause the disorders concerning the function of many organs. Alternations in vascular permeability cause the loss of plasma to extravascular compartments which leads to hemoconcentration. The hematocrit increases by about $2 \%$ for every $1{ }^{\circ} \mathrm{C}$ decline in temperature (Danzl and Pozos 1994), and a normal hematocrit in a case of moderately or severely hypothermic individual indicates pre-existing anemia or blood loss. It has also been indicated that hypothermia can cause marrow suppression and progressive marrow failure as well as introduction of erythroid hypoplasia and sideroblastic anemia (O'Brien et al. 1982; Rosenkranz 1985).

The direct influence of hypothermia concerns the enzymic reactions of both intrinsic and extrinsic pathways of the clotting cascade (Rohrer and Natale 1992), and, as a result, coagulopathy can occur. Prothrombin time, thrombin time, and partial thromboplastin time are affected by the low temperature. Appropriate management involves rewarming, rather than administration of exogenous clotting factors (Reed et al. 1992). On a number of occasions, a disseminated intravascular coagulopathy has been reported without any apparent cause other than the hypothermia itself (Breen et al. 1988); such a situation may result from the release of tissue thromboplastin from ischaemic tissue (Mahajan et al. 1981), or the circulatory collapse could turn out to be the major factor (Carden and Nowak 1982). Moreover, hypothermia can impair both the endothelial synthesis of prostacyclin $\left(\mathrm{PGI}_{2}\right)$ and its inhibitory action connected to platelet aggregation, promoting platelet activation and thrombosis (Mikhailidis et al. 1983). What is more, platelet production of thromboxane $\mathrm{B}_{2}$ depends on the temperature, and it encourages a decline in platelet activity when the temperature decreases (Easterbrook and Davis 1985).

As there is no sufficient number of professional literatures about the influence of hypothermia on the electrical properties of biological membranes, we researched the changes of surface charge density of blood cells after fatal accidental hypothermia. It is a continuation of a systematic study of the electrical properties of postmortem human erythrocyte and thrombocyte membranes, which was examined by Figaszewski and co-workers (Kotyńska et al. 2012; Szeremeta et al. 2013; Petelska et al. 2015). The researchers conducted their experience using a microelectrophoresis method since it is one of the fundamental analytical tools in case of biological studies. The electrophoretic mobility measurements were carried out with a $\mathrm{pH}$ range of $2-11$. From our perspective, the results we obtained can be helpful both in the interpretation as well as understanding of the processes which take place on biological membrane surfaces after fatal accidental hypothermia.

\section{Materials and Methods}

Blood (pH 6.6) was obtained from sober individuals during autopsies conducted at the Forensic Medicine Department at the Medical University of Bialystok in the year 2013. The examination was based on 10 selective examples of fatal hypothermia (five men and five women, mean age 43.7 years, range 23-71) autopsied in the year 2013. Approval for this study was granted by the Ethics Review Board of the Medical University of Bialystok (No. R-I-002/ 533/2010).

Blood was obtained from all individuals during autopsies conducted at the Forensic Medicine Department at the Medical University of Bialystok in the year 2013. Blood was routinely obtained from the femoral vein, inserted into chemically and biologically clean glass containers, and donated to the Department of Electrochemistry at the University of Bialystok. The donated samples were analyzed comparatively with control samples taken from live individuals that are from healthy volunteers.

\section{Preparation of Erythrocytes from Blood}

Erythrocytes were isolated from $2 \mathrm{ml}$ of liquid whole blood by centrifugation at $900 \times g$ for $8 \mathrm{~min}$ at room temperature. The supernatant thrombocyte-rich plasma was removed and saved for subsequent processing, while the erythrocytes were washed three times with isotonic saline $(0.9 \%$ $\mathrm{NaCl})$ at $3000 \times g$ for $15 \mathrm{~min}$. After the final wash, the erythrocyte pellet was resuspended in isotonic saline for electrophoretic measurement.

\section{Preparation of Thrombocytes from Plasma}

Thrombocyte-rich plasma was centrifuged at $4000 \times g$ for $8 \mathrm{~min}$. The supernatant plasma was removed and discarded. The thrombocyte pellet was washed three times 
with isotonic saline by centrifugation at $3000 \times g$ for $15 \mathrm{~min}$. After the final wash, thrombocytes were resuspended in isotonic saline for electrophoretic measurement.

All solutions and cleaning procedures were performed using water which was purified thanks to Milli-Qll system (18.2; Millipore, Billerica, MA).

\section{Microelectrophoretic Mobility Measurements}

The electrophoretic mobility of erythrocyte or thrombocyte vesicles in suspension was measured using Doppler velocimetry laser and a Zetasizer Nano ZS (Malvern Instruments, Malvern, UK) apparatus. Measurements were carried out as a function of $\mathrm{pH}$. Cell membranes were suspended in $\mathrm{NaCl}$ solution and titrated to the desired $\mathrm{pH}$ using $\mathrm{HCl}$ or $\mathrm{NaOH}$. The reported values represent the average of at least six measurements performed at a given $\mathrm{pH}$.

Based on electrophoretic mobility measurements, the surface charge density was determined using Eq. 1 (Alexander and Johnson 1949):

$\delta=\frac{\eta \cdot u}{d}$

where $\eta$ is the viscosity of the solution, $u$ is the electrophoretic mobility, and $d$ is the diffuse layer thickness.

The diffuse layer thickness (Barrow 1996) was determined according to the formula:

$d=\sqrt{\frac{\varepsilon \cdot \varepsilon_{0} \cdot R \cdot T}{2 \cdot F^{2} \cdot I}}$

where $R$ is the gas constant, $T$ is temperature, $F$ is the Faraday number, $I$ is the ionic strength of $0.9 \% \mathrm{NaCl}$, and $\varepsilon \varepsilon_{0}$ is the permeability of the electric medium.

\section{Results and Discussion}

The grounds for investigations on membrane association phenomena were constituted by electrophoretic mobility measurements conducted after fatal accidental hypothermia occurred in blood cells. The experiments were performed at several $\mathrm{pH}$ values using $0.155 \mathrm{M} \mathrm{NaCl}$ which served as a supporting electrolyte. Then the electrophoretic mobility values were converted to surface charge density. It was done by Eq. 1 presented in section Materials and Methods.

The surface charge densities of erythrocytes of control and fatal accidental hypothermia are plotted as a function of $\mathrm{pH}$ in Fig. 1. The experiment indicated an increase in positive charge of the erythrocytes membrane after fatal accidental hypothermia when compared to control erythrocytes when acid solution was used. On the other hand, an increase in negative charge after fatal accidental hypothermia when compared to control erythrocytes was indicated in case of using basic solution.

Table 1 presents isoelectric point and surface charge density values for human erythrocytes. These data were obtained using electrophoresis method. The presentation of data has a form of mean standard deviation. The data were a subject of analysis conducted based on standard statistical analysis.

Whereas fatal accidental hypothermia has specific and strong influence on the acid-base balance, the body temperature decreases opposite thing happens to solubility oxygen and carbon dioxide levels and the activity of histidine imidazole ring buffer included in the hemoglobin increases. According to estimations, in a closed system with every degree drop in temperature, the $\mathrm{pH}$ is increased by 0.015 - Rosenthal formula (Rosenthal 1948). Thanks to that formula, one could probably provide explanation of the
Fig. $1 \mathrm{pH}$ dependence of surface charge density of erythrocytes

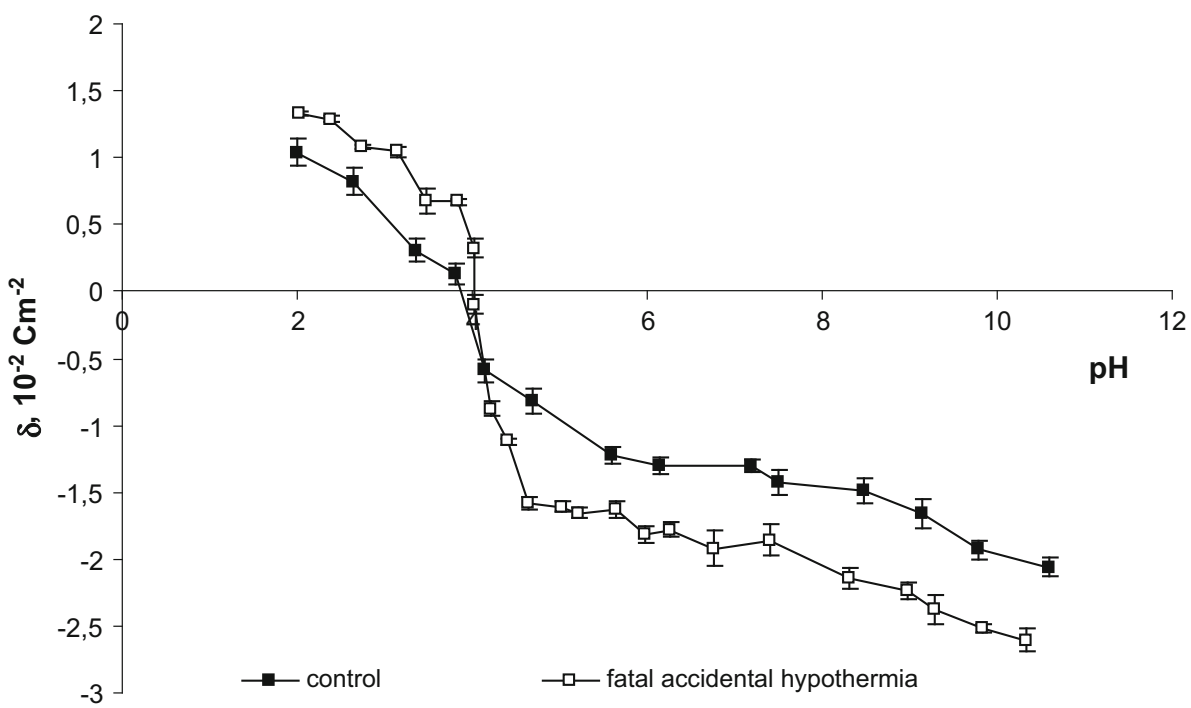


Table 1 The surface charge density and isoelectric point values for human erythrocytes (control and fatal accidental hypothermia)

\begin{tabular}{|c|c|c|c|}
\hline \multirow[t]{2}{*}{ Groups } & \multirow[t]{2}{*}{ Isoelectric point } & \multicolumn{2}{|c|}{ Surface charge density $\left[10^{-2} \mathrm{C} \mathrm{m}^{-2}\right]$} \\
\hline & & At low $\mathrm{pH}$ values & At high $\mathrm{pH}$ values \\
\hline $\begin{array}{l}\text { Control (Kotyńska et al. 2012; } \\
\text { Szeremeta et al. 2013) }\end{array}$ & 3.72 & $1.039 \pm 0.103$ & $-2.063 \pm 0.059$ \\
\hline Fatal accidental hypothermia & 3.80 & $1.334 \pm 0.117$ & $-2.603 \pm 0.091$ \\
\hline
\end{tabular}

$\mathrm{pH}$ levels ( 6.6) indicated in the blood samples we collected. Consequently, $\mathrm{pH}$ increases at an early stage of hypothermia and what usually decreases is the pressure of the carbon dioxide. In the following stages, one can observe the hyperkalemia associated with acidosis and renal failure (Mallet 2002). What is more, in case of accidental fatal hypothermia, alternations of surface charge density can be also connected to the production of ketone bodies in the liver as an alternative energy source and hormonal stimulation of hypothalamic-pituitary-adrenal axis. The latter also advances concentration of ketone bodies, mainly $\beta$-hydroxybutyric acid in sober individuals (Palmiere et al. 2014a; Bańka et al. 2014). However, if fatal accidental hypothermia occurs, the oxygen flow to tissues decreases which results in an energetic deficit that can compensate for only activation of anaerobic ATP supply pathway (Pasteur effect). Due to the rapid depletion of fermentable substrate together with the accumulation of deleterious end-products, like $\mathrm{H}^{+}$ions (Boutilier 2001) anaerobic ATP production cannot sustain the pre-existing energy demands of cells, as well as tissues. Alternatively, differential permeabilities of the major ions themselves, with little or no direct involvement of the $\mathrm{Na}+/ \mathrm{K}+$ ATPase (Plesnila et al. 2000), could be the cause of the membrane changes (destabilization) during accidental hypothermia.
The surface charge densities of thrombocytes of the control and after fatal accidental hypothermia are plotted as a function of $\mathrm{pH}$ in Fig. 2. The decrease in positive charge of the membrane in a $\mathrm{pH}$ range 2-4 when compared with control membrane is a result of hypothermia. Within $\mathrm{pH}$ range 4-9, hypothermia leads to an increase in negative charge of the thrombocytes membrane, and there is a little shift of the isoelectric point of the membrane towards low $\mathrm{pH}$ values. Table 2 contains isoelectric point and surface charge density values for human thrombocyte.

In our view, such alternations may be, to much extent, dictated by the same processes as described in the case of erythrocytes. Quite the opposite, the differences observed in surface charge densities could have been cause by coagulopathy, and it manifested itself by a gradual impairment of platelet function $\left(\mathrm{TXB}_{2}\right)$, thrombocytopenia, decrease in the activity of clotting factors, and increased fibrinolytic activity. However, one must bear in mind hypothermia can impair both the endothelial synthesis of prostacyclin $\left(\mathrm{PGI}_{2}\right)$ and its inhibitory action on platelet aggregation, promoting platelet activation. In other words, platelets secrete granule products that include calcium (actives coagulation proteins) and ADP (mediates further platelets aggregations and degranulation). Phospholipids complexes are also exposed by activated platelets which
Fig. 2 pH dependence of surface charge density of thrombocytes

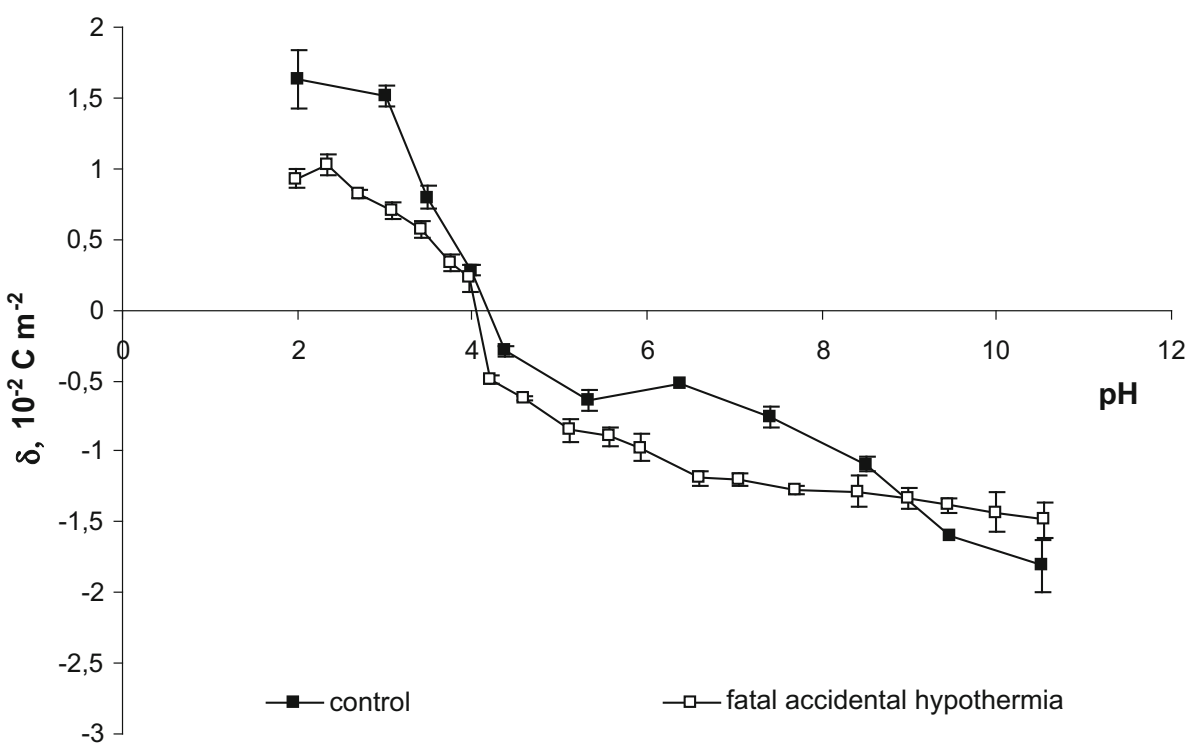


Table 2 The surface charge density and isoelectric point values for human thrombocytes (control and fatal accidental hypothermia)

\begin{tabular}{lccc}
\hline Groups & Isoelectric point & Surface charge density $\left[10^{-2} \mathrm{C} \mathrm{m}^{-2}\right]$ & At high pH values \\
\cline { 3 - 4 } & & At low pH values & $-1.810 \pm 0.185$ \\
$\begin{array}{l}\text { Control (Kotyńska et al. 2012; } \\
\begin{array}{l}\text { Szeremeta et al. 2013) } \\
\text { Fatal accidental hypothermia }\end{array}\end{array}$ & 4.20 & $1.628 \pm 0.206$ & $-1.486 \pm 0.128$ \\
\hline
\end{tabular}

are the source of an important surface for coagulationprotein activation (Kumar et al. 2007). However, at this stage, we are not able to declare which mechanism leads to the examined surface charge density of platelets in fatal accidental hypothermia in greater degree.

Acknowledgments The research was supported by the Medical University of Bialystok (Grant ANZ-0604-113-21676L).

Open Access This article is distributed under the terms of the Creative Commons Attribution 4.0 International License (http://crea tivecommons.org/licenses/by/4.0/), which permits unrestricted use, distribution, and reproduction in any medium, provided you give appropriate credit to the original author(s) and the source, provide a link to the Creative Commons license, and indicate if changes were made.

\section{References}

Alexander AE, Johnson P (1949) Colloid science. Clarendon Press, Oxford

Bańka K, Teresiński G, Buszewicz G (2014) Free fatty acids as markers of death from hypothermia. Forensic Sci Int 234:79-85

Barrow GM (1996) Physical chemistry. McGraw-Hill Inc, New York

Boutilier RG (2001) Mechanisms of cell survival in hypoxia and hypothermia. J Exp Biol 204:3171-3181

Breen EG, Coghlan JG, Egan E, McCarthy CF (1988) Impaired coagulation in accidental hypothermia of the elderly. Age Ageing 17:343-346

Bright F, Winskog C, Walker M, Byard RW (2013) Why are Wischnewski spots not always present in lethal hypothermia? The results of testing a stress-reduced animal model. J Forensic Leg Med 20:785-787

Carden DL, Nowak RM (1982) Disseminated intravascular coagulation in hypothermia. JAMA 247:2099

Danzl DF, Pozos RS (1994) Accidental hypothermia. N Engl J Med 331:1756-1760

Easterbrook PJ, Davis HP (1985) Thrombocytopenia in hypothermia: a common but poorly recognised complication. Br Med J 291:23

Hirvonen J (1976) Necropsy findings in fatal hypothermia cases. Forensic Sci 8:155-164

Hirvonen J, Huttunen P (1982) Increased urinary concentration of catecholamines in hypothermia deaths. $\mathrm{J}$ Forensic Sci 27:264-271

Ishikawa T, Yoshida C, Michiue T, Perdekamp MG, Pollak S, Maeda $\mathrm{H}$ (2010) Immunohistochemistry of catecholamine in the hypothalamic-pituitary-adrenal system with special regard to fatal hypothermia and hyperthermia. Leg Med 12:121-127

Jakubeniene M, Chaker GA, Becelis A, Malakiene D, Raudys R (2009a) Investigation of calcium and sodium in postmortem material as biochemical markers defining the cause of death from hypothermia. Leg Med 11:S304-S306

Jakubeniene M, Irnius A, Chaker GA, Paliulis JM, Bechelis A (2009b) Post-mortem investigation of calcium content in liver, heart, and skeletal muscle in accidental hypothermia cases. Forensic Sci Int 190:87-90

Kotyńska J, Petelska AD, Szeremeta M, Niemcunowicz-Janica A, Figaszewski ZA (2012) Changes in surface charge density of blood cells after sudden unexpected death. J Membr Biol 245:185-190

Kumar V, Abbas AK, Fausto N, Mitchell R (2007) Robbins basic pathology, 8th edn. Sauders Elsevier, Philadelphia

Li DR, Quan L, Zhu BL, Ishikawa T, Michiue T, Zhao D, Yoshida C, Chen JH, Wang Q, Komatsu A, Azuma Y, Maeda H (2009) Evaluation of postmortem calcium and magnesium levels in the pericardial fluid with regard to the cause of death in medicolegal autopsy. Leg Med 11:S276-S278

Mahajan SL, Myers TJ, Baldini MG (1981) Disseminated intravascular coagulation during rewarming following hypothermia. JAMA 245:2517-2518

Mallet ML (2002) Pathophysiology of accidental hypothermia. QJM Med 95:775-785

Mant AK (1964) Some post-mortem observation in accidental hypothermia. Med Sci Law 4:44-46

Mant AK (1969) Autopsy diagnosis of accidental hypothermia. J Forensic Med 16:126-129

Mikhailidis DP, Hutton RA, Jeremy JY, Dandona P (1983) Hypothermia and pancreatitis. J Clin Pathol 36:483-484

O'Brien RC, Amess JAL, Mollin DL (1982) Recurrent thrombocytopaenia, erythroid hypoplasia and sideroblastic anaemia associated with hypothermia. Br J Haematol 51:451-456

Palmiere C, Mangin P, Werner D (2014a) Postmortem distribution of 3-beta-hydroxybutyrate. J Forensic Sci 59:161-166

Palmiere C, Teresiński G, Hejna P (2014b) Postmortem diagnosis of hypothermia. Int J Legal Med 128:607-614

Petelska AD, Kotyńska J, Figaszewski ZA (2015) The effect of fatal carbon monoxide poisoning on the equilibria between cell membranes and the electrolyte solution. J Membr Biol 248:157-161

Plesnila N, Muller E, Guretzki S, Ringel F, Staub F, Baethmann A (2000) Effect of hypothermia on the volume of rat glial cells. J Physiol 523:155-162

Quan L, Zhu BL, Ishikawa T, Michiue T, Zhao D, Ogawa M, Maeda $\mathrm{H}$ (2010) Postmortem serum erythropoietin level as a marker of survival time in injury deaths. Forensic Sci Int 200:117-122

Reed RL 2nd, Johnson TD, Hudson JD, Fischer RP (1992) The disparity between hypothermic coagulopathy and clotting studies. J Trauma 33:465-470

Rohrer MJ, Natale AM (1992) Effect of hypothermia on the coagulation cascade. Crit Care Med 20:1402-1405

Rosenkranz L (1985) Bone marrow failure and pancytopenia in two patients with hypothermia. South Med J 78:358-359

Rosenthal T (1948) The effect of temperature on the $\mathrm{pH}$ of blood and plasma in vitro. J Biol Chem 173:25-30 
Szeremeta M, Petelska AD, Kotyńska J, Niemcunowicz-Janica A, Figaszewski ZA (2013) The effect of fatal carbon monoxide poisoning on the surface charge of blood cells. J Membr Biol 246:467-471

Tsokos M, Rothschild MA, Madea B, Rie M, Sperhake JP (2006) Histological and immunohistochemical study of Wischnewsky spots in fatal hypothermia. Am J Forensic Med Pathol 27:70-74

Zhu BL, Ishida K, Quan L, Taniguchi M, Oritani S, Li DR, Fujita MQ, Maeda H (2002) Postmortem serum uric acid and creatinine levels in relation to the causes of death. Forensic Sci Int 125:59-66

Zhu BL, Ishikawa T, Michiue T, Li DR, Zhao D, Quan L, Maeda H (2005) Evaluation of postmortem urea nitrogen, creatinine and uric acid levels in pericardial fluid in forensic autopsy. Leg Med 7:287-292

Zhu BL, Ishikawa $\mathrm{T}$, Michiue $\mathrm{T}$, Li DR, Zhao D, Oritani $\mathrm{S}$, Kamikodai Y, Tsuda K, Okazaki S, Maeda H (2006a) Postmortem cardiac troponin $\mathrm{T}$ levels in the blood and pericardial fluid. Part 1. Analysis with special regard to traumatic causes of death. Leg Med 8:86-93
Zhu BL, Ishikawa T, Michiue T, Li DR, Zhao D, Kamikodai Y, Tsuda K, Okazaki S, Maeda H (2006b) Postmortem cardiac troponin T levels in the blood and pericardial fluid. Part 2: analysis for application in the diagnosis of sudden cardiac death with regard to pathology. Leg Med 8:94-101

Zhu BL, Ishikawa T, Michiue T, Li DR, Zhao D, Tanaka S, Kamikodai Y, Tsuda K, Okazaki S, Maeda H (2007a) Postmortem pericardial natriuretic peptides as markers of cardiac function in medico-legal autopsies. Int J Legal Med 121:28-35

Zhu BL, Ishikawa T, Michiue T, Li DR, Zhao D, Bessho Y, Kamikodai Y, Tsuda K, Okazaki S, Maeda H (2007b) Postmortem cardiac troponin I and creatine kinase MB levels in the blood and pericardial fluid as markers of myocardial damage in medicolegal autopsy. Leg Med 9:241-250

Zhu BL, Ishikawa T, Michiue T, Li DR, Zhao D, Quan L, Oritani S, Bessho Y, Maeda H (2007c) Postmortem serum catecholamine levels in relation to the cause of death. Forensic Sci Int 173:122-129 